\title{
A GEOSPATIAL REFERENCE FRAMEWORK FOR A UNIVERSITY CAMPUS: A CASE STUDY FOR MANAGING STUDENT SURVEYED TOPOGRAPHIC DATA
}

\author{
D. Fraser, S. Sepehr, E. Stefanakis \\ Department of Geodesy and Geomatics Engineering, University of New Brunswick, Canada - fraser@unb.ca
}

Technical Commission II

KEY WORDS: Geospatial reference framework, Topographic survey, University campus.

\begin{abstract}
:
This presentation describes a geospatial reference framework for managing student surveyed topographic data of a university campus. This topographic data is collected annually by Geodesy and Geomatics Engineering (GGE) students at the University of New Brunswick (UNB) as part of the requirements for a UNB course. Examples of the type of features collected include: buildings, roads, sidewalks, walking paths, bike racks, parking lots and parking designation (e.g. accessibility parking). The applications and the information products built for managing this student surveyed topographic data can be viewed as a geospatial reference framework for this GGE survey camp.
\end{abstract}

\section{INTRODUCTION}

Each year, GGE students conduct a topographic survey of part of UNB campus as part of the course requirements for GGE2013; this course is often referred to as Survey Camp II. Students work in groups and each group is assigned a specific area of UNB campus. Each area contains many types of topographic features including buildings, sidewalks, streets, parking lots, green areas, trees, lamp posts, benches, flower beds, etc. Each group is responsible for creating a digital CAD file and a hardcopy topographic plan of their survey area and these two products are typically created using CAD software. In comparison with orthophotos -- acquired for the City of Fredericton (New Brunswick, Canada) in 2008, resolution is approximately $15 \mathrm{~cm}$-- the student's survey data generally may be described as: (a) the collected data tends to correctly depict the location of features on the UNB campus; and (b) the data is complete, that is, contains the topographic features that students were responsible for surveying.

This data, however, does contain several issues [Sepehr, 2014]. Some examples are: (a) groups do not use a common naming scheme to identify features - for example, one group may refer to buildings as BLGD as oppose to another group which may use BC (building corner); (b) features are not necessary surveyed in a consistent manner - for example, road boundaries may be surveyed as intersect of asphalt with curb or bottom of curb, etc.; (c) groups do not necessarily collect all the same features - for example, one group may survey accessibility information (parking, doors, wheelchair ramps) whereas another group may not and (d) the topographic data itself does contain topological errors - for example, crosswalks do not end at road/parking lot boundaries yet instead may either overlap with sidewalks, lawns, etc. or end before the boundary (undershoot).

This paper will briefly discuss some of the components of the geospatial reference framework and show two of the information products that were generated from the topographic data.

The paper is organized as follows. Section 2 briefly introduces the spatial reference framework and its components. Section 3 introduces one of these components, namely topographic feature specifications. Finally, Section 4 concludes the discussion by highlighting two GIS exercises that make use of student surveyed topographic data.

\section{SPATIAL FRAMEWORK}

The applications and the information products built for managing this topographic data can be viewed as a geospatial reference framework for this GGE survey camp. This is because the framework provides students with the specifications that they need to consider when performing the topographic survey, the various tools and methods necessary for validating their topographic surveys, and finally, the geographical repository (i.e. GIS database) used for managing this data. One of the components of this framework - topographic feature surveying specifications and is now briefly described.

\section{TOPOGRAPHIC FEATURE SURVEYING SPECIFICATIONS}

Before developing these specifications, the following were considered: (a) there are many topographic features on UNB Campus (see Figure 1) -- which features should be surveyed? (b) topographic features can be referred to by several different names (e.g. walking areas can be referred to as sidewalks, walkway, paths, etc.) - what names and codes should we use to identify the features? and (c) - for most features, we can survey its centre (or centre line) or its boundaries (bike racks, benches, roads, etc.) -- how should we survey the features of interest? 


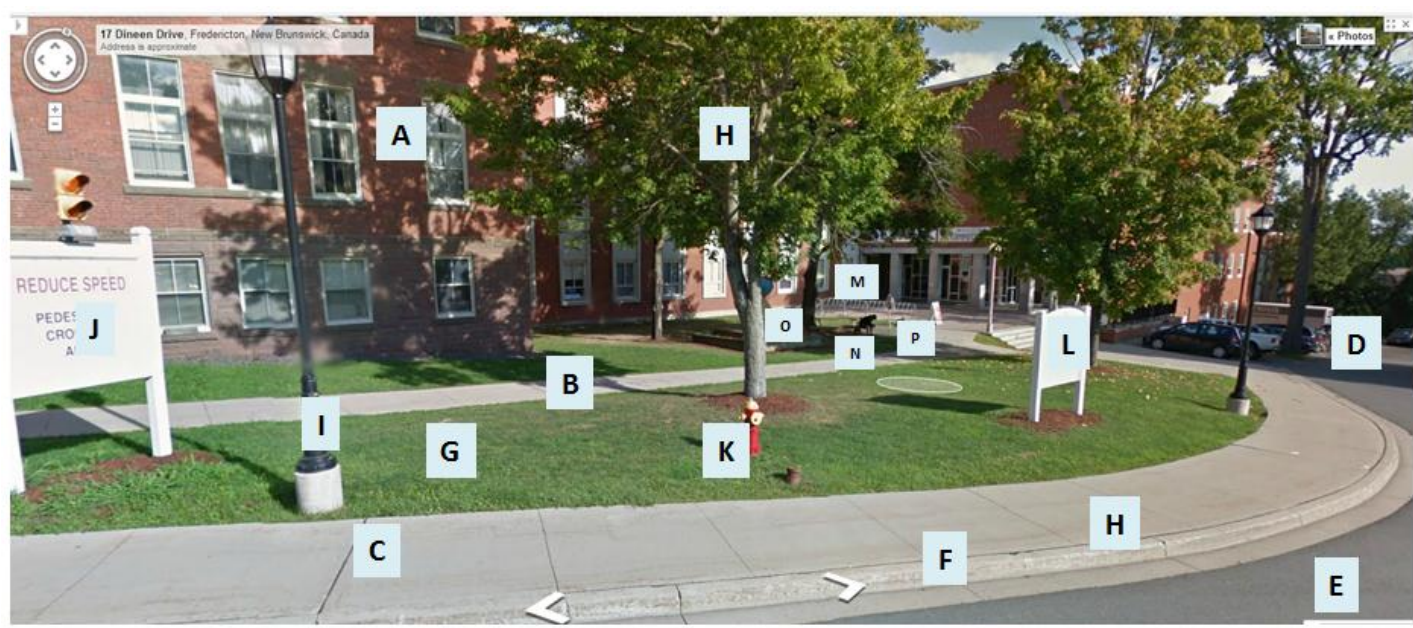

\begin{tabular}{|l|l|l|l|l|l|l|l|}
\hline A & Building & E & Road & I & Lamp & M & Bike Rack \\
\hline B & Walkway & F & Curb & J & UNB TrafficSign & N & Bench \\
\hline C & Sidewalk & G & Lawn & K & Fire Hydrant & O & Monument \\
\hline D & Parking Lot & H & Tree & L & BuildingSign & P & Ashtray \\
\hline
\end{tabular}

Figure 1.Topographic features for an area on UNB Campus

\begin{tabular}{|l|l|l|l|}
\hline Feature & Code & Survey & Description/ Comments/ How to survey \\
\hline Buildings & BC & Boundary & $\begin{array}{l}\text { Survey the building corners - for how to survey, refer to reference guide } \\
\text { Surveying UNB Campus Topo Features - Slide "Surveying Buildings" }\end{array}$ \\
\hline Building & BO & $\begin{array}{l}\text { Boundary - } \\
\text { projected }\end{array}$ & $\begin{array}{l}\text { To survey this feature, refer to reference guide Surveying UNB Campus Topo } \\
\text { Features - Slide "Surveying Building Overhangs" }\end{array}$ \\
\hline Building Overhang & Point & $\begin{array}{l}\text { Building Entrance that is wheelchair accessible - for how to survey, refer to } \\
\text { reference guide Surveying UNB Campus Topo Features - Slide "Surveying } \\
\text { Building Accessibility" }\end{array}$ \\
\hline $\begin{array}{l}\text { Building accessible } \\
\text { (automatic) door }\end{array}$ & BA & UNB Building sign. \\
\hline Building sign & BS & Point &
\end{tabular}

Figure 2.Extract from reference guide "Topographic Features List” [GGE 2014b]

To determine which features to survey and how to survey these features, the following resources were consulted / considered: the course instructor, former course students, deliverables from previous camps, purpose of the spatial framework and online campus maps. The results of this process was the creation of two topographic feature surveying specifications documents (a) a topographic feature list (see Figure 2) -- contains features to survey, code for feature and description on what to survey a feature (survey boundary of feature vs. its centre); and (b) a surveying reference guide (see Figure 3) - illustrations showing how to survey various features on UNB campus. The objectives of the specifications were to: (a) ensure both consistency amongst groups - that is, all groups use same: (i) naming convention (e.g. building survey points are coded as BC (for building corners, not BD or BUILD or BLDG); (ii) surveying convention (e.g. park benches, bike racks surveyed as single feature representing its centre) and (iii) survey same features (e.g. if a topographic feature is listed in specifications in a groups survey area, this feature will be surveyed); and (b) ensure that surveyed feature is properly encoded in the topographic dataset. It should be noted that the topographic feature list in Figure 2 represents the minimum set of features to be surveyed and that groups can survey additional features if group warrants as necessary. A few notable exceptions of features that were not included in the feature list includes road curbs, drainage beds around buildings and "non-permanent" features (recycling/trash bins).

\section{INFORMATION PRODUCTS}

There are two main objectives of this geospatial reference framework, namely: (a) to improve the processes of collecting, storing, retrieving and representing student surveyed topographic data and (b) create information products for UNB. Several examples of the information products include: (a) resources for assisting students with performing topographic surveys (such as those shown in Figures 2 and 3); and (b) GIS training materials for UNB students; and (c) a detailed UNB campus basemap.

These training materials are designed to provide practical training in GIS. They also have the additional benefit of: (a) showing $1^{\text {st }}$ year GGE students some of the surveying work that they will do in survey camp II; and (b) allowing senior GGE students to work with the data that they collected in Survey Camp II in advanced GIS courses. GGE students typically complete survey camp II in their sophomore $\left(2^{\text {nd }}\right)$ year and advanced GIS courses in either their junior (3rd) or senior year. 


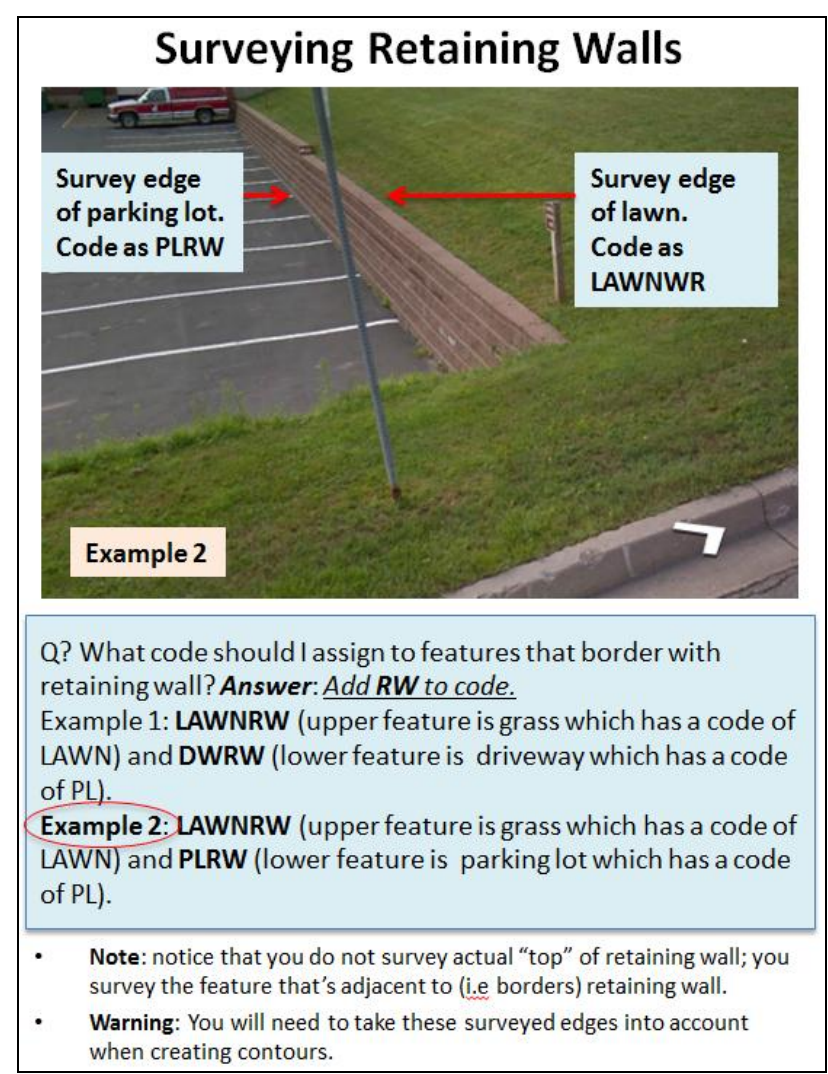

Figure 3. Extract from reference guide "Surveying UNB Campus Topographic Features" [GGE 2014a]

Examples of training materials are two tutorial based GIS exercises, namely: (a) Introduction to GIS and (b) Advanced Editing and Introduction to Topology in GIS. In the first exercise, the students both symbolize and create a map from a set of topographic survey points. This exercise is used designed to introduce the students to using GIS software. A sample input (topographic feature points) and output (map) from this exercise is shown in Figures 4 and 5. It should be noted that the maps shown in Figures 5 and 7 were created by students and, as such, some of the symbology and/or surround information might be presented in a different manner if created by a certified cartographer.

The second exercise is designed to introduce students to both advanced editing and spatial geometric relationships (topology) in GIS. For this exercise, the students correct spatial geometric relationships such as those shown in Figure 6, for example (a) overshoots and undershoots -- such as walkways (sidewalks, paths, crosswalks) and road/parking intersections; (b) feature overlap -- such as cross walks overlapping sidewalks and green areas, etc.. There results for this exercise is a both a topologically consistent dataset and a hardcopy map such as shown in Figure 7.

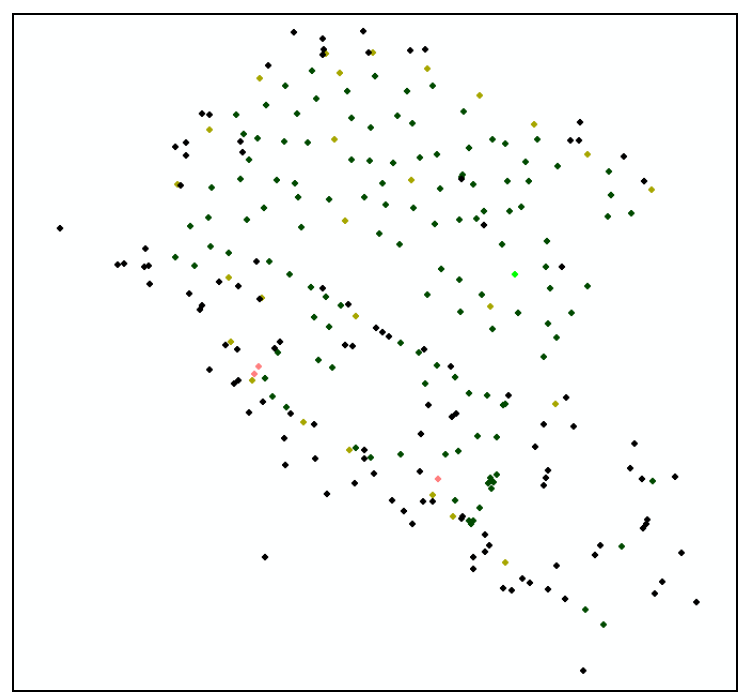

Figure 4. Topographic Survey data used in Introduction to GIS Exercise.

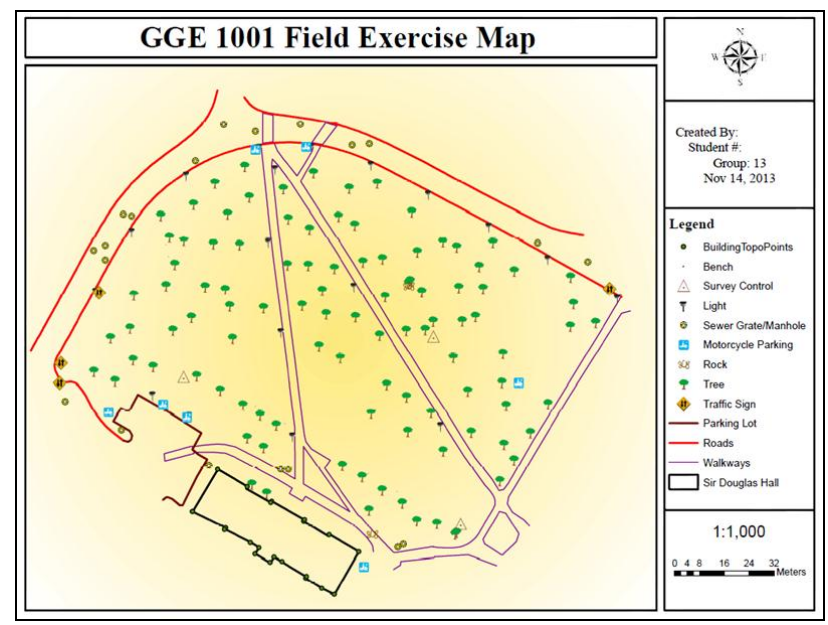

Figure 5. Hardcopy map deliverable for Introduction to GIS exercise.

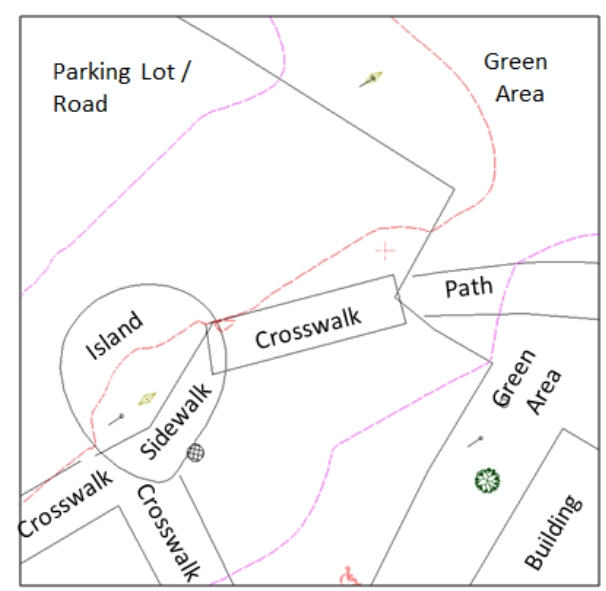

Figure 6. Examples of topology errors in student surveyed topographic data. 


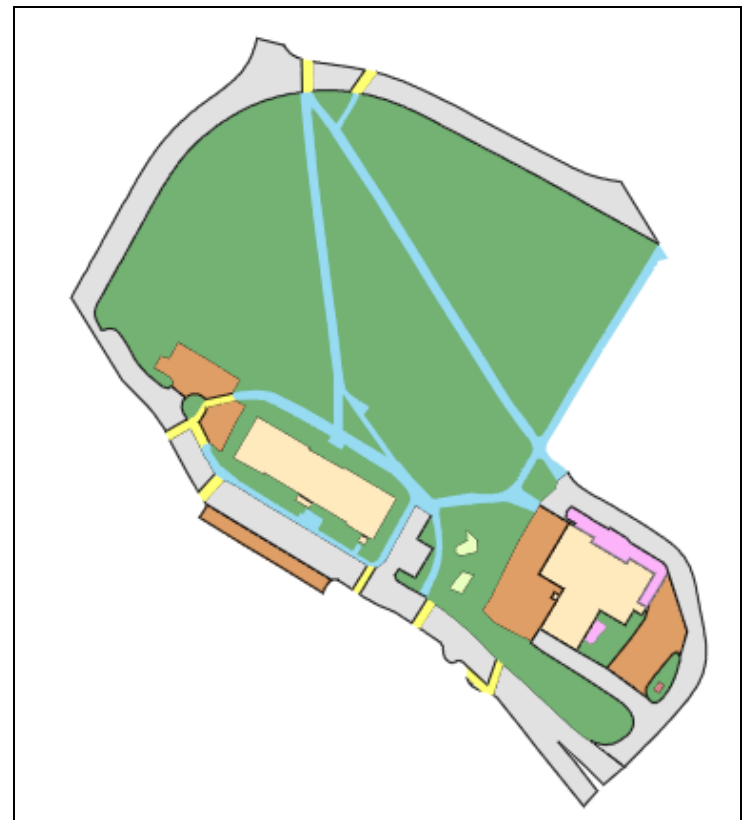

Figure7. Extract from map deliverable for Advanced Editing and Introduction to Topology Exercise.

\section{REFERENCES}

GGE (2014a), "Surveying UNB Campus Topographic Features", GGE2013 Course Materials, Department of Geodesy \& Geomatics Engineering (GGE), University of New Brunswick, Fredericton, Canada

GGE (2014b), "Topographic Features List", GGE2013 Course Materials, Department of Geodesy \& Geomatics Engineering (GGE), University of New Brunswick, Fredericton, Canada

Sepehr S. (2013) "Development of a Geospatial Reference Framework: A Case Study for the UNB-GGE Survey Camp", Master of Science in Engineering Thesis, Department of Geodesy \& Geomatics Engineering (GGE), University of New Brunswick, Fredericton, Canada 